\title{
E-cigarettes in Europe: does regulation swing from overcautious to careless?
}

\author{
Frank Henkler $\cdot$ Andreas Luch
}

Received: 20 March 2014 / Accepted: 3 June 2014 / Published online: 11 June 2014

(C) Springer-Verlag Berlin Heidelberg 2014

When e-cigarettes first arrived in Europe, these products were met with initial skepticism. Although these devices had always been acknowledged to avoid major hazards that are associated with smoking, questions about associated health risks remained to be answered. The issue of regulation was raised very early, leading to discussions on a proper classification of these products. Until now, it proves very difficult to reach consensus between regulators in European countries, and between stakeholders either representing anti-tobacco and addiction control initiatives or the growing community of e-cigarette users.

Initially, concerns were raised against nicotine, humectants, and additives. Emerging in e-cigarettes, such ingredients were not well defined, and thus, any risk assessment did not allow for general conclusions applicable to the entire product spectrum. Some of the uncertainties have been addressed by well-designed studies in recent years, including Goniewicz et al. (2014), Etter et al. (2013), and McAuley et al. (2012). All of these studies confirmed a markedly reduced toxicity of e-cigarettes when compared to conventional tobacco products. Still, some toxicological risks remain for e-cigarette smokers, and aerosols might also affect the quality of indoor environments. Toxicological issues include, but are not limited to exposure against volatile compounds and ultrafine particles (Pellegrino et al. 2012; Schripp et al. 2012) and aerosolized nicotine (Schober et al. 2013). Concerns have also been raised with

\footnotetext{
F. Henkler · A. Luch $(\square)$

Department of Chemical and Product Safety, German Federal Institute for Risk Assessment (BfR), Max-Dohrn-Strasse 8-10, 10589 Berlin, Germany e-mail: andreas.luch@bfr.bund.de

F. Henkler

e-mail: Frank.Henkler@bfr.bund.de
}

regard to allergenic flavors, contaminants as well as additives that may encompass pharmacologically active compounds (Hadwiger et al. 2010). A proper risk assessment also requires further caution as users may have the possibility to modify commercial liquids when using refillable cartridges. The issue of e-cigarettes serves as very good example of how the assessments of associated toxicological risks are a matter of perspective. On the one hand, these products may be useful for established smokers as less harmful substitute, and perhaps even as cessation aid. On the other side, these devices are likely to convey significant and unnecessary health risks for nonsmokers who start to engage in smoking using e-cigarettes based on the perception of a rather harmless amusement. Although there is some consensus that acute toxicological risks are small, little is known about addiction and corresponding long-term effects. However, chronic nicotine exposure needs to be regarded as important risk factor. The question of whether e-cigarettes can promote cardiovascular diseases is still open, since data on long-term exposure are not yet available. Analogies with Swedish oral smokeless tobacco do not suggest strongly enhanced risks (Hansson et al. 2009, 2012), while data from the Atherosclerosis Risk in Communities (ARIC) study rather suggest such an association between the use of smokeless tobacco and increased cardiovascular disease incidence in cigarette nonsmokers (Yatsuya et al. 2010). Beyond that, it should be noted that e-cigarette smokers are being exposed to additional risk factors for cardiovascular diseases such as volatile substances and ultrafine particles, which are not present at considerable levels in smokeless tobacco. Although these risks should not be overemphasized as relevant for adult and habitual tobacco smokers, it is equally important not to trivialize any putative and real health hazard, in particular for cigarette non- or rarely smokers. 
The question whether e-cigarettes are increasingly and particularly used by former nonsmokers can not yet conclusively be answered. Prevalence among adolescents is also a matter of ongoing debate. Although still low, the numbers of high school students who had tried e-cigarettes doubled during the period of 2011-2012 (CDC 2013). In the best case, this could only reflect a desire of young people for experimentation. However, experiences from the USA and South Korea suggest that approximately $75 \%$ of current e-cigarette smokers do use conventional tobacco products in parallel (CDC 2013; Lee et al. 2014). A possible value of such devices in harm reduction for adolescents, as suggested by Etter (2013), should therefore be questioned in light of these data. Some details of the Korean study, authored by Lee et al. (2014), are further of interest: Related to increased age, numbers for both ever and current "e-cigarette only users" remain constantly low, whereas dual users increase by fourfold to fivefold in both categories. The number of dual users can only rise when smokers either start to vapor or "e-cigarette only users" begin to smoke tobacco. If the number of dual users rises because of smokers who discover e-cigarettes as substitute, a certain increase in "e-cigarette only users" should also be expected in elder student groups. However, this was not the case. Dual users might therefore be at least partially recruited from e-cigarette smokers who start to use tobacco cigarettes. These trends need to be observed further, before reliable conclusions can be drawn. Although current data do not necessarily imply e-cigarettes as gateway to tobacco, such possible effects can not be ruled out. Again, concerns should not be trivialized or simply be disqualified as efforts from the tobacco control activist side, "who disapprove a smoking cessation tool that, being used without their participation or approval, threatens their status" (Etter 2013).

Beside putative risks, the hazards of nonrestricted trading of liquids that contain high amounts of dissolved nicotine are predominant and real. The framework of risk assessment did initially focus on cartridges that contain $1 \mathrm{ml}$ of liquid. But newly developed refillable e-cigarettes comprise $10 \mathrm{ml}$ or even more that may contain $200-300 \mathrm{mg}$ of purest nicotine. The lethal dose of nicotine was recently discussed in this journal (Mayer 2014). Although we can accept the arguments for adjusting the estimates, a possible content of 200-300 mg nicotine in a single product remains unacceptable for such consumer products that are unrestrictedly sold over the counter. When applying the newly calculated estimates for a lethal dosage as proposed by Mayer (6.5-13 mg/kg body weight), $100 \mathrm{mg}$ of nicotine still poses a lethal risk under certain circumstances, and in particular and certainly for children. Notably, in Germany, such liquids are not even requested to be labeled as "TOXIC," provided that concentrations remain just below $10 \mathrm{mg} / \mathrm{ml}$ (Lower Saxony Ministry of Food, Health and
Consumer Protection 2013). Accidental intoxications are feasible, especially since these liquids contain flavors that are typically used for food. Further, dermal exposure might also occur, since consumers need to handle these bottles directly while refilling the reservoirs. This problem of acute toxicity is perhaps less relevant for disposables, since these devices usually do not contain more than $1-2 \mathrm{ml}$ of liquid. Since consumers can hardly come into direct contacts, the risks for acute intoxications are rather small. However, disposables can be linked to other hazards. Our recent study presented in this issue of the journal "Archives of Toxicology" demonstrated that carbonyls are being formed when liquid levels decrease. This could require implementing of additional safety features. Further, disposal or recycling needs to be well organized, since these devices contain both batteries and toxic liquids.

Previous attempts to regulate e-cigarettes might reflect divided perceptions on risk and potential benefits. In Germany, Federal State authorities are responsible for classification of marketed products. When e-cigarettes first emerged, no regulation was pursued. Instead, state authorities tried to classify these products within the existing legal framework. Three principal options appeared possible:

1. Regulation as medical device. Regulation of e-cigarettes as medical product was suggested, due to the potential auxiliary function and aid of low-level nicotine exposure in the course of tobacco smoking cessation. Such regulation might have focused on pharmacological properties of nicotine, but not on therapeutic claims or intentions. Although several Federal States in Germany were supportive for such a kind of classification, major uncertainties arose. For instance, classification as medical device would have raised general concerns on whether or not these products can be legally marketed. In several states, this has been successfully challenged in administrative courts. Until now, efforts to regulate e-cigarettes as medical devices are widely regarded as attempts to pursue prohibition by traders and consumer activist groups. In fact, such a classification offers some advantages. These might include mandatory rules for nicotine and other ingredients, as well as the possibility to prescribe e-cigarettes for smokers who are willing to quit tobacco.

2. Regulation as tobacco product. This option did not play a major role in previous discussions in Germany. Nevertheless, in 2013, the Provincial Court Frankfurt classified e-cigarettes as tobacco products, based on the reasoning that the nicotine was derived from tobacco plants. As tobacco legislation would allow specified regulation of distinct product categories, this might be an appropriate option to ensure both accessibility for adult users and sufficient standards for health and 
consumer protection. For example, herbal cigarettes, which do not contain tobacco or nicotine that originates from tobacco plants, are nevertheless covered by the German tobacco legislation.

3. Regulation as consumer product. Since the regulation as medical product has become unfeasible without modification of the legal framework, e-cigarettes are currently only required to meet the very basal provisions of consumer product safety. This framework, however, is not considered sufficient for any other commodity intended for human consumption, as for example food, tobacco, or cosmetics. Very recently, it was decided by Federal States in Germany to apply the existing legislation on declaration and labeling of chemicals to e-cigarettes. In fact, this minimum requirement is rather basic because these devices are well available on the market for now some time. After years of longish discussions, such achievements can hardly be regarded as important contribution to consumer protection though.

Today, most stakeholders accept that e-cigarettes require a regulatory framework that sets mandatory rules for vaporizing agents. In fact, our investigation presented in this issue demonstrated the necessity to authorize comparably safe compounds (e.g., glycerol and propylene glycol), because this would also mean to set restrictions for more problematic alternatives (e.g., ethylene glycol). Such a framework should also cover major ingredients, e.g., flavors, and specify rules for labeling as well as technical parameters and safety features. No consensus has yet been reached on how to address the nicotine contents. Because regulation proved complicated throughout Europe, the European commission (EC) took initiative in 2012 and included e-cigarettes in the drafted proposal for a novel Tobacco Product Directive. In fact, the EC proposed regulation for nicotine-containing products as medical devices. Limits to exempt products from authorization were set to $2 \mathrm{mg}$ nicotine per unit or $4 \mathrm{mg}$ nicotine $/ \mathrm{ml} \mathrm{liq-}$ uid. In light this perspective, the recent statement of Mayer (2014) that "concerns about ingestion of small amounts of tobacco products or diluted nicotine-containing solutions are unjustified" becomes comprehensible. But was this initial proposal really overcautious? If the requirements for e-cigarettes to gain authorization would be really designed as a realistic option, and not to be meant to eliminate such products from the market, such a proposal might have the chance to ensure a high level of consumer protection. Instead, on October 8, 2013, the European Parliament decided to take another direction by amending a proposal that dismissed any upper limit with regard to the nicotine contents in these products (EU 2013). Only an upper nicotine concentration of $30 \mathrm{mg}$ nicotine/ml liquid has been defined. Although obviously intended for e-cigarettes only, the decision of the European Parliament is likely to prevent any relevant restriction for the entire spectrum of nicotine-containing products. Further, no mandatory health warning was adopted to address the alarming risks of high nicotine dosage. Again, this decision was aimed to authorize a barely restricted trade for products such as refillables that might contain up to $300 \mathrm{mg}$ nicotine or more. Considering this current stage of discussion at the EU level, it becomes difficult to abstain from the conclusion that health risks of nicotine-containing products had been trivialized by some European legislators. After conclusion of the trilogy negotiations between European Council, Commission, and Parliament, a revised proposal was approved on February 26, 2014. Now, the upper limit for nicotine was set at $20 \mathrm{mg} / \mathrm{ml}$, or $200 \mathrm{mg}$ per $10 \mathrm{ml}$ refill bottle. Further mandatory health warnings and safety features have also been introduced.

\section{References}

CDC (2013) Notes from the field: electronic cigarette use among middle and high school students-United States, 2011-2012. MMWR Morb Mortal Wkly Rep 62:729-730

Etter JF (2013) Should electronic cigarettes be as freely available as tobacco? Yes. Br Med J 346:f3845

Etter JF, Zäther E, Svensson S (2013) Analysis of refill liquids for electronic cigarettes. Addiction 108:1671-1679

EU (2013) Amendments adopted by the European Parliament on 8 October 2013 on the proposal for a directive of the European Parliament and of the Council on the approximation of the laws, regulations and administrative provisions of the Member States concerning the manufacture, presentation and sale of tobacco and related products $(\mathrm{COM}(2012) 0788$ - C7-0420/2012 - 2012/0366(COD)). See: http://www.europarl.europa.eu/sides/getDoc.do?pubRef=-//EP// TEXT+TA+P7-TA-2013-0398+0+DOC+XML+V0//EN

Goniewicz ML, Knysak J, Gawron M, Kosmider L, Sobczak A, Kurek J, Prokopowicz A, Jablonska-Czapla M, Rosik-Dulewska C, Havel C, Jacob P 3rd, Benowitz N (2014) Levels of selected carcinogens and toxicants in vapour from electronic cigarettes. Tob Control 23:133-139

Hadwiger ME, Trehy ML, Ye W, Moore T, Allgire J, Westenberger B (2010) Identification of amino-tadalafil and rimonabant in electronic cigarette products using high pressure liquid chromatography with diode array and tandem mass spectrometric detection. $\mathbf{J}$ Chromatogr A 1217:7547-7555

Hansson J, Pedersen NL, Galanti MR, Andersson T, Ahlbom A, Hallqvist J, Magnusson C (2009) Use of snus and risk for cardiovascular disease: results from the Swedish Twin Registry. J Intern Med 265:717-724

Hansson J, Galanti MR, Hergens MP, Fredlund P, Ahlbom A, Alfredsson L, Bellocco R, Eriksson M, Hallqvist J, Hedblad B, Janssom JH, Nilsson P, Pedersen N, Lagerros YT, Östergren PO, Magnusson C (2012) Use of snus and acute myocardial infarction: pooled analysis of eight prospective observational studies. Eur J Epidemiol 27:771-779

Lee S, Grana RA, Glantz SA (2014) Electronic cigarette use among Korean adolescents: a cross-sectional study of market penetration, dual use, and relationship to quit attempts and former smoking. J Adolesc Health 54:684-690 
Lower Saxonia Ministry of Food, Health and Consumer Protection (2013) Rechtliche Einstufung Elektrischer Zigaretten und darin verwendeter Lösungen Gem. RdErl. d. ML, d. MS u. d. MU v. 16. 12. 2013-202-44220-33 (see: http://www.nds-voris.d e/jportal/?quelle $=$ jlink\&query=VVND-287000-ML-20131216$\mathrm{SF} \& \mathrm{psml}=$ bsvorisprod.psml\&max $=$ true)

Mayer B (2014) How much nicotine kills a human? Tracing back the generally accepted lethal dose to dubious self-experiments in the nineteenth century. Arch Toxicol 88:5-7

McAuley TR, Hopke PK, Zhao J, Babaian S (2012) Comparison of the effects of e-cigarette vapor and cigarette smoke on indoor air quality. Inhal Toxicol 24:850-857

Pellegrino RM, Tinghino B, Mangiaracina G, Marani A, Vitali M, Protano C, Osborn JF, Cattaruzza MS (2012) Electronic cigarettes: an evaluation of exposure to chemicals and fine particulate matter (PM). Ann Ig 24:279-288

Schober W, Szendrei K, Matzen W, Osiander-Fuchs H, Heitmann D, Schettgen T, Jörres RA, Fromme H (2013) Use of electronic cigarettes (e-cigarettes) impairs indoor air quality and increases FeNO levels of e-cigarette consumers. Int J Hyg Environ Health [Epub ahead of print]

Schripp T, Markewitz D, Uhde E, Salthammer T (2012) Does e-cigarette consumption cause passive vaping? Indoor Air 23:25-31

Yatsuya H, Folsom AR, ARIC Investigators (2010) Risk of incident cardiovascular disease among users of smokeless tobacco in the Atherosclerosis Risk in Communities (ARIC) study. Am J Epidemiol 172:600-605 